\title{
SIMULATION OF THE TEMPERATURE DISTRIBUTION IN CRYSTALS GROWN BY CZOCHRALSKI METHOD
}

\author{
M.P. Dudukovic and P.A. Ramachandran \\ Washington University \\ st. Louis, MO 63130
}

Production of perfect crystals, free of residual strain and dislocations and with prescribed dopant concentration, by the Czochralski method is possible only if the complex, interacting phenomena that affect crystal growth in a $\mathrm{Cz}-\mathrm{puller}$ are fully understood and quantified. Natural and forced convection in the melt, thermocapillary effect and heat transfer in and around the crystal affect its growth rate, the shape of the crystal-melt interface and the temperature gradients in the crystal. (1) In this work we have concentrated on describing the heat transfer problem in the crystal and between the crystal and all other surfaces present in the crystal pulling apparatus.

This model and computer algorithm are based on the following assumptions: i) only conduction occurs in the crystal (experimentally determined conductivity as a function of temperature is used), ii) melt temperature and the melt-crystal heat transfer coefficient are available (either as constant values or functions of radial position), iii) pseudo-steady state is achieved with respect to temperature gradients, iv) crystal radius is fixed, $v$ ) both direct and reflected radiation exchange occurs among all surfaces at various temperatures in the crystal puller enclosure.

This is the first model to replace the simple stefan's law for radiation from the melt and crystal surface to the ambient with the Gebhart's enclosure theory which accounts for both direct and reflected radiation. Available emissivities were used. The position of the melt-crystal interface is not assumed a priori but is computed as part of the solution as a locus of points where the flux continuity (heat flux from the melt plus the rate of release of the heat of crystallization is balanced by heat conduction into the crystal) is satisfied at the melting point isotherm.

Galerkin finite elements with triangular basic cells and linear trial functions are used to reduce the problem to a set of nonlinear algebraic equations. These are solved by an iterative scheme both for the temperatures and the melt-crystal interface position. (2)

Using 10 elements in the radial direction and 30 in the axial proved adequate to achieve the desired accuracy and resulted in 352 unknowns. Doubling the number of nodes did not affect the results. One minute of CPU time on a DEC20 computer was required per iteration. Convergence was obtained usually in less than 8 iterations.

The model calculates the axial and radial temperature profiles in the crystal and the position of the melt-crystal interface as a function of the input parameters (melt temperature, crucible wall temperature, temperatures of 
various surfaces in the enclosure, pulling rate, crystal radius). Comparison with the results in the literature (2) which used stefan's law to describe radiative heat transfer show that these underpredict the axial temperature profile and the radial temperature gradients. Thus, proper accounting for reflected radiation seems important. The model also indicates that an increase in pulling rate at other fixed parameters would tend to make the melt-crystal interface more concave to the crystal (i.e. melt protrudes into the crystal). The same trend is caused by an increase in meit or crucible temperature.

These final predictions regarding the melt-crystal interface need further verification. This can only be done by incorporating the thermocapillary effect, to describe the meniscus at the crystal-melt-gas line of contact, and by evaluating the convective patterns in the melt to obtain proper melt temperature and heat transfer coefficient profiles. This work is currently in progress.

(1) Kobayashu, N., Heat Transfer in Cz Crystal Growth (W.R. Wilcox, ed.), Marcel Dekker, Inc. (1981).

(2) Ramachandran, P.A. and Dudukovic, M.P., "Simulation of Temperature Distribution in Crystals Grown by Czochralski Method," J. Crystal Growth (accepted for publication, 1984). Williams, G. and Rousser, P.E., J. Crystal Growth, 64, 448 (1983). 


\section{Oxygen Content in Silicon}
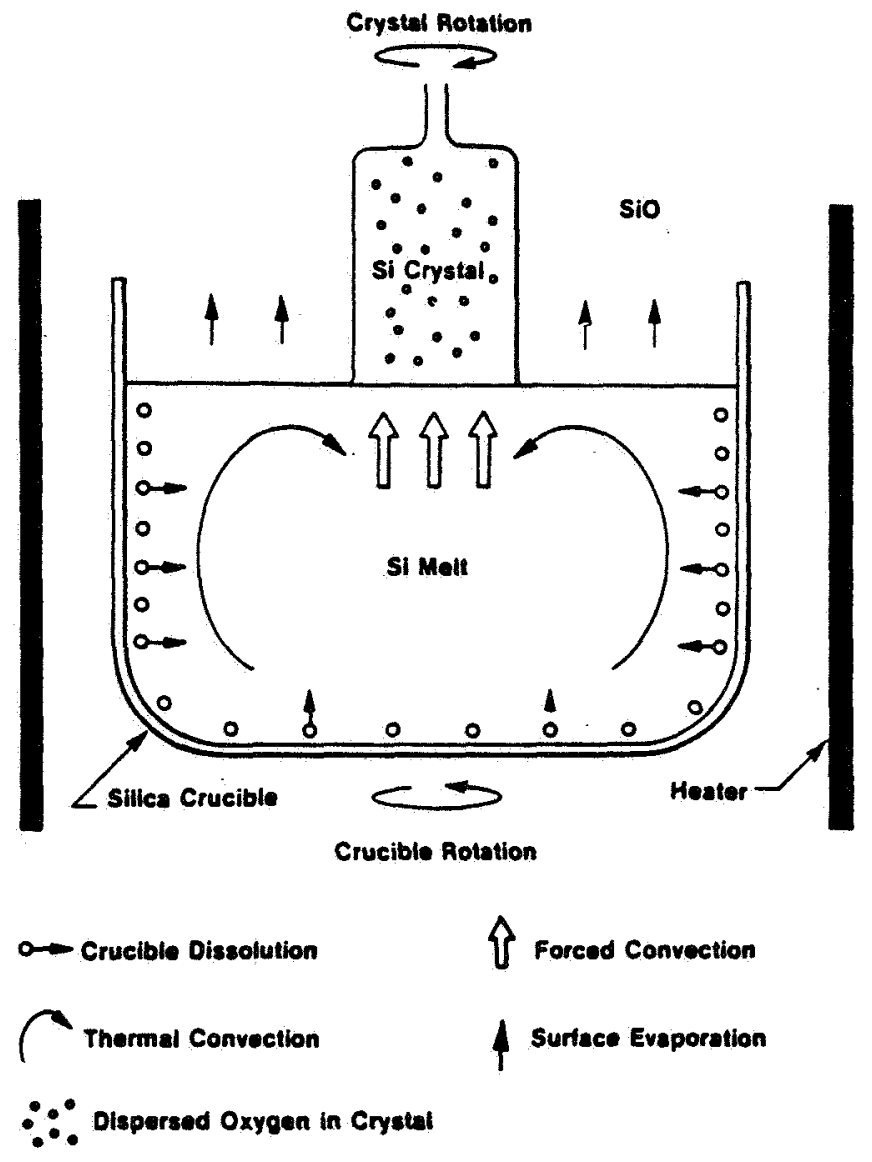

ใ Foreed Convection

A Surtuce Evaporation

Fig. 3-Schematic drawing illustrating the spatial relationship of separate factors that affect oxygen content in silicon during crystal growth. (After a drawing in Benson, et al. [25].)

R. R. Huff, Solid State Technology, Feb. ' 83 


\section{Problem Complexities}

1. Temperature distribution in melt and crystal are coupled.

2. Complex flow patterns in melt

1. forced convection

2. natural convection

3. thermocapillary effect

3. Floating boundary, interface shape cannot be fixed a priori

4. Radiation interactions 


\section{Variables Affecting $\mathrm{Cz}$ Growth}

i) geometric variables including crucible shape, enclosure shape, heater position and shape, etc.;

ii) controllable operating variables such as pulling rate, crystal rotation rate, crucible rotation rate, gas flow rate, furnace power;

iii) process variables such as melt depth, crystal diameter, etc.

Due to the complex interaction among many variables their interrelationship cannot be understood in a quantitative sense through any number of experiments unless experimental results are interpreted through an appropriate model of the system. 
Ultimate Objective Is to Produce a Perfect Crystal CRYSTAL

- FREE OF RESIDUAL STRAIN

- FREE OF DISLOCATIONS

. UNIFORMLY DOPED

ONCE A PROPER MODEL IS ESTABLISHED AND

VERIFIED THE EFFECT OF CHANGES IN VARIOUS VARIABLES

ON CRYSTAL QUALITY CAN BE ASSESSED MORE READILY

WITH FAR FEWER EXPERIMENTS, OPTIMIZATION OF THE

OPERATION BECOMES POSSIBLE. 


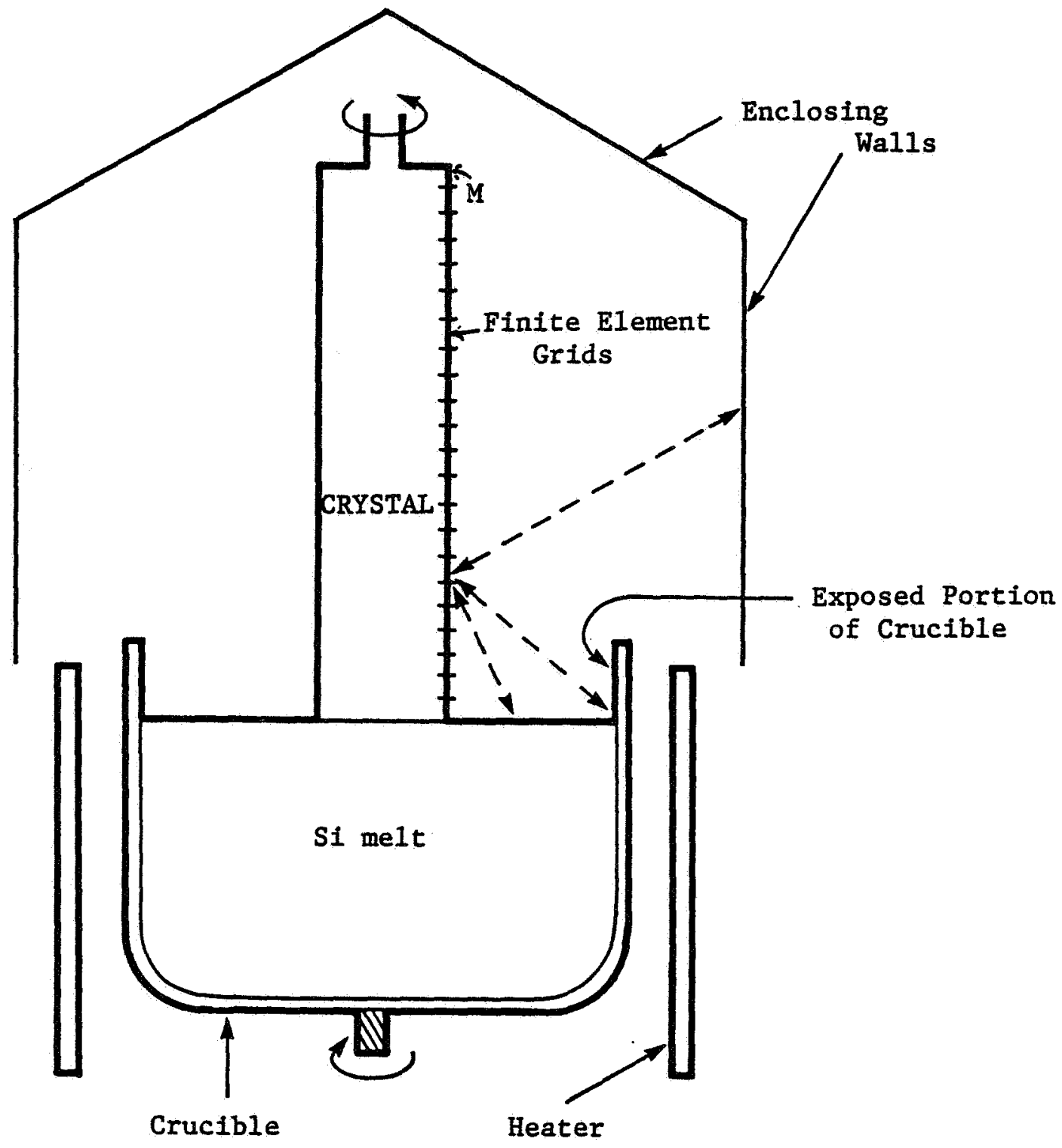

Figure 1. Schematic of Czochralski single crystal pulling apparatus, -- indicates radiation interaction between various surfaces 


\section{Enclosures for Crystal Problem}

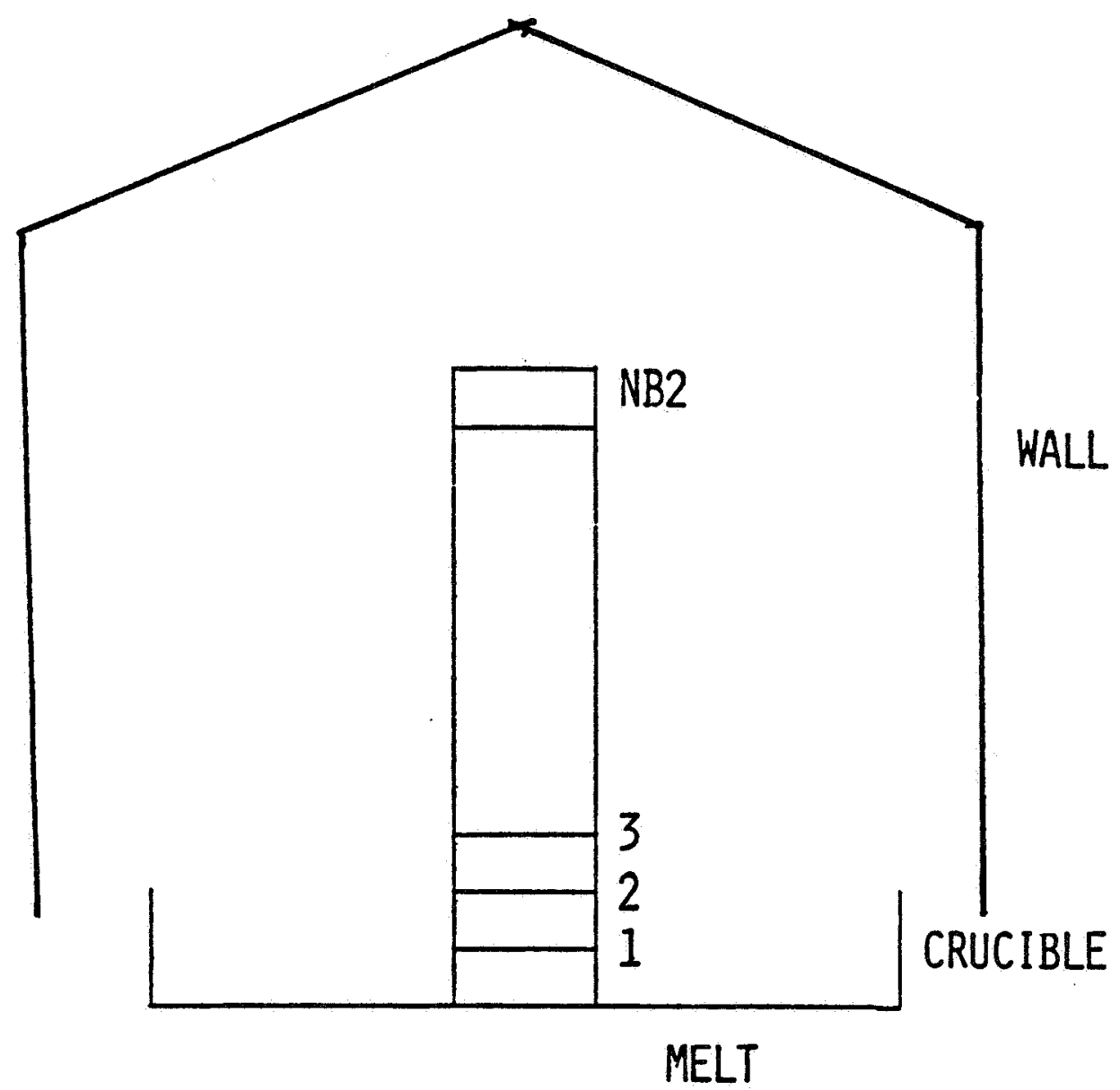

CRYSTAL IS DIVIDED INTO NB2 ELEMENTS. THESE PROVIDE NB2 SURFACES. THREE ADDITIONAL SURFACES ARE CONSIDERED AS SHOWN ABOVE

$$
N=N B 2+3
$$


Model Equations

$$
\frac{1}{r} \frac{\partial}{\partial r}\left(k_{e} r \frac{\partial T}{\partial r}\right)+\frac{\partial}{\partial z}\left(k_{e} \frac{\partial T}{\partial Z}\right)-v \rho C_{p} \frac{\partial T}{\partial z}=0
$$

Cylindrical Surface

$$
\begin{aligned}
& k_{e}\left(\frac{d T}{d n}\right)_{R}+n_{c}\left(T-T_{d}\right)+a_{R}=0 \\
& \text { Top Surface } \\
& k_{e}\left(\frac{d T}{d z}\right)_{L}+h_{C}\left(T-T_{a}\right)+a_{R}=0
\end{aligned}
$$


Calculation of Radiation Flux

GEBHART METHOD IS USED

CONSIDER AN ENCLOSURE WITH N SURFACES, EACH SURFACE BEING AT TEMPERATURE $T_{k}$. THE HEAT LOSS FROM. SURFACE $k$ IS

$$
\begin{aligned}
& Q_{k}=A_{k} \epsilon_{k} \sigma T_{k}^{4}-\sum_{j=1}^{N} A_{j} \epsilon_{j} \sigma T_{j}^{4} G_{j k} \\
& q_{k}=\frac{Q_{k}}{A_{k}}
\end{aligned}
$$

156 
CALCULATION $G_{j k}(j=1$ TO $N)$ FOR ANY GIVEN SURFACE $k$

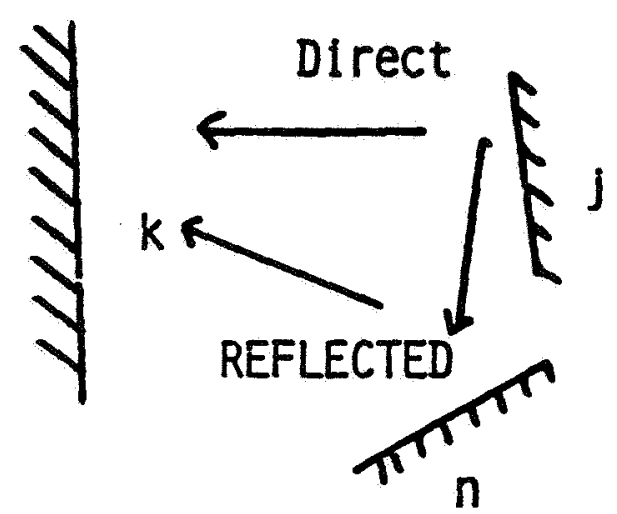

SURFACE $k$ RECEIVES BOTH DIRECT AS WELL AS REFLECTED RADIATION FROM SURFACE $J$. DIFFUSE REFLECTION IS ASSUMED. 
DIRECT RADIATION ( $\mathrm{j}$ to $\mathrm{k}$ )

$$
\epsilon_{j} \sigma T_{j}^{4} A_{j} F_{j k} \epsilon_{k}
$$

REFLECTED RADIATION ( $\mathrm{j}$ to $\mathrm{n}$ to $\mathrm{k}$ )

$$
\begin{aligned}
& \left(\epsilon_{j} \sigma T_{j}{ }^{4} A_{j} F_{j n}\right)\left(\rho_{n}\right)\left(G_{n k}\right) \\
& (j \text { to } n) \text { (REFLECTION) ( } n \text { to } k \text { ) }
\end{aligned}
$$

\section{TOTAL RADIATION FROM J}

$\epsilon_{j} \sigma T_{j}^{4} A_{j}$

$\underline{G_{j k} \text { FACTOR }}$

$$
G_{j k}=F_{j k} \epsilon_{k}+\sum_{n=1}^{N} F_{j n} \rho_{n} G_{n k}
$$




$$
\begin{aligned}
F_{i j}=0 \text { for } i & \leq N B 2 \\
& \text { and } \\
j & \leq N B 2
\end{aligned}
$$

HENCE THE CALCULATION OF $G_{j k}$ CAN BE SIMPLIFIED.

$$
\left(\begin{array}{l}
\underline{g_{1}} \\
\underline{g_{2}}
\end{array}\right)=\left(\begin{array}{l}
\underline{0} \\
\underline{p}
\end{array}\right)+\left(\begin{array}{ll}
\underline{0} & \underline{B_{2}} \\
B_{3} & \underline{B_{4}}
\end{array}\right)\left(\begin{array}{c}
\underline{g_{1}} \\
\underline{g_{2}}
\end{array}\right)
$$




\section{LINEARIZED FORM OF BOUNDARY CONDITION}

$$
\begin{aligned}
& k_{e}\left(\frac{d T}{d r}\right)_{R}+h_{c}\left(T-T_{a}\right)+\varepsilon_{k} \sigma\left(T_{k}{ }^{4}-\frac{1}{\varepsilon_{k} A_{k}} \sum_{j=1}^{N} A_{j} \varepsilon_{j} \sigma T_{j}{ }^{4} G_{j k}\right)=0 \\
& h_{R}\left(T-T_{\text {eff }}\right)
\end{aligned}
$$

AN EFFECTIVE TEMPERATURE FOR RADIATION CAN BE DEFINED

$$
\begin{aligned}
& T_{e f f, R}=\left[\frac{1}{\varepsilon_{k} A_{k}} \sum_{j=1}^{N} A_{j} \varepsilon_{j} \sigma T_{j}{ }^{4} G_{j k}\right]^{1 / 4} \\
& q_{R}=\varepsilon \sigma\left(T^{4}-T_{e f f}^{4}\right)=h_{R}\left(T-T_{e f f}\right) \\
& h_{R}=\varepsilon \sigma\left(T^{2}+T_{e f f}^{2}\right)\left(T+T_{e f f}\right)
\end{aligned}
$$




\section{Finite-Element Equations}

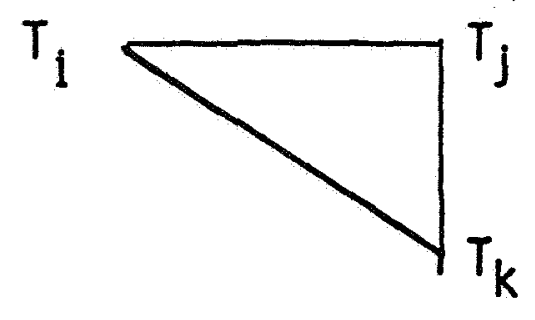

$$
=\quad\left(\begin{array}{c}
T_{i} \\
T_{j} \\
T_{k}
\end{array}\right)=\underline{P}
$$

$\underline{K}$ and $\underline{P}$ depend on nodal coordinates, physical properties, and the boundary conditions imposed on the element.

Equations for each element can be assembled and the resulting global matrix can be solved for all the nodal temperatures. 
TO START ITERATION SCHEME USE ONE-DIMENSIONAL MODEL

WITH FINITE PECLET NUMBER

(Wilcox \& Duty, J. Heat Transfer, 1966)

$\frac{T(z)-T_{a}}{T_{m}-T_{a}}=\theta=\exp \left\{\frac{\frac{V \rho C_{p} R}{k}-\sqrt{\left(\frac{V \rho C_{p}^{R}}{k}\right)}+\frac{8 h R}{k}}{2} \frac{z}{R}\right\}$

WHERE WE TAKE

$\mathrm{h} \approx 3 \mathrm{~h}_{\text {convection }}$

PULLING RATE EFFECT NEGLIGIBLE

(SMALI PECLET NUMBER) WHEN

$$
\left(\frac{\mathrm{V} \rho \mathrm{C}_{\mathrm{p}} \mathrm{R}^{2}}{\mathrm{k}}\right)^{2}<<\frac{8 \mathrm{hR}}{\mathrm{k}}
$$




\section{Program Structure}

1. INPUT

2. NODE AND ELEMENT NUMBERING

3. ASSUME TRIAL VALUES FOR TEMPERATURES FOR FIRST ITERATION

3a. CALCULATE G FACTORS

3b. CALCULATE

$T_{\text {eff, }}, h_{r}, a_{c}$, etc.

4. SOLVE FINITE ELEMENT EQUATIONS FOR. NODAL TEMPERATURES

5. CHECK FOR CONVERGENCE

6. $T_{\text {New }}=W_{1} T_{\text {calculated }}$

$$
+\left(1-W_{1}\right) T_{\text {assumed }}
$$

7. LOCATE $Z$ POSITIONS WHERE TEMPERATURE IS EQUAL TO TO MELTING POINT (INTERFACE SHAPE).

8. REPEAT CALCULATIONS TILL CONVERGENCE IS OBTAINED. 


\section{Special Features}

- INTERFACE SHAPE CALCULATED AND NOT ASSUMED

- TWO DIMENSIONAL MODEL

- ENCLOSURE THEORY PERMITS DETAILED ANALYSIS OF RADIATION HEAT TRANSFER

- EFFECTS OF ADDITIONAL HEATING AND COOLING SURFACES CAN EASILY BE SIMULATED

- PHYSICAL PROPERTIES ASSUMED AS A FUNCTION OF TEMPERATURE 

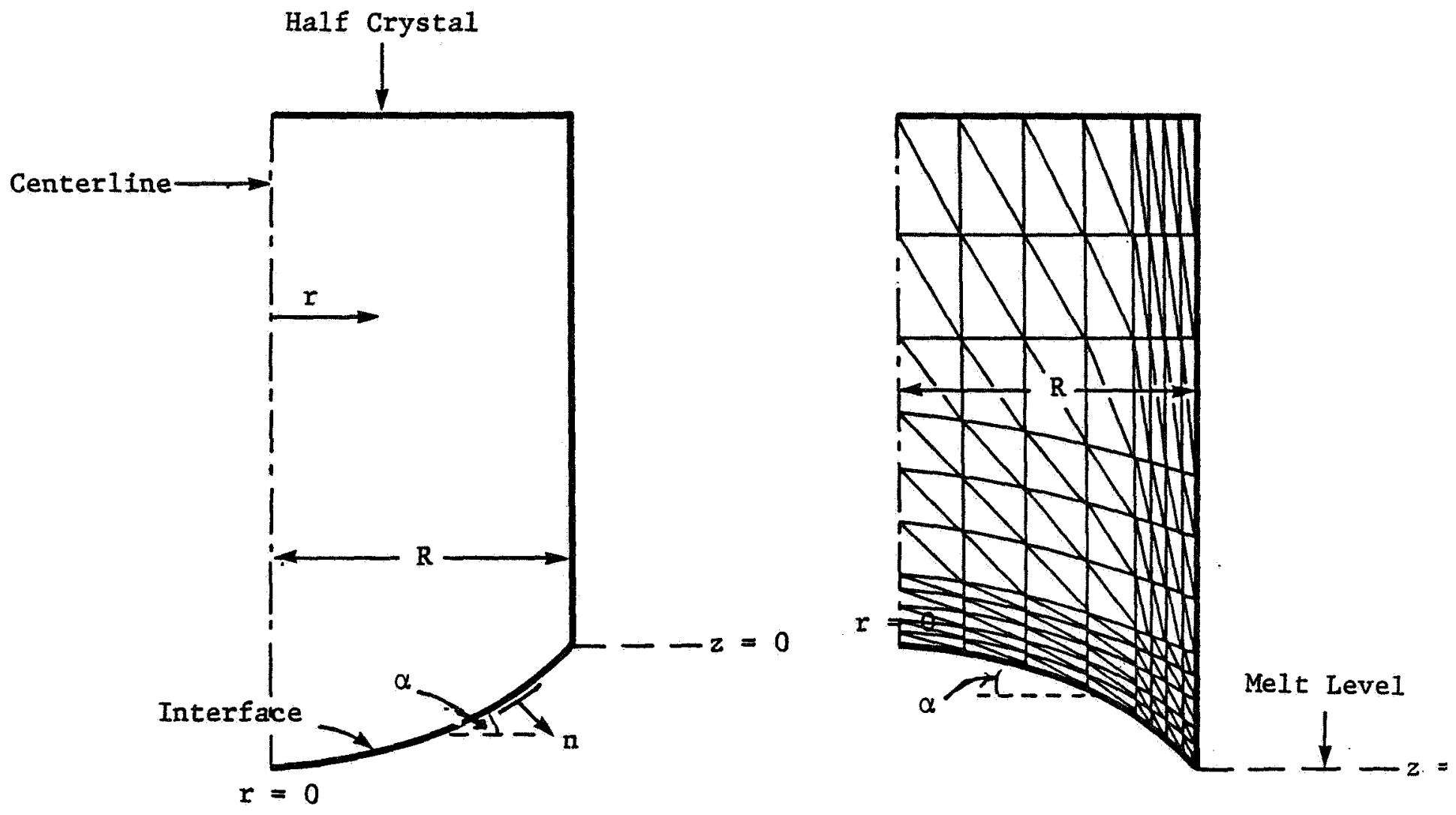

Figure 2. Interface shapes commonly encountered; also defines the various geometric parameters and indicates the schematic of finite element meshes used 
Table 2. Parameter Values Used in Illustrative Application Example

\begin{tabular}{|c|c|}
\hline radius of crystal & $4 \mathrm{~cm}$ \\
\hline height of crystal & $17 \mathrm{~cm}$ \\
\hline crystal pulling rate & $0.002 \mathrm{~cm} / \mathrm{s}$ \\
\hline crucible radius & $10 \mathrm{~cm}$ \\
\hline height of exposed crucible & $3 \mathrm{~cm}$ \\
\hline wa11 area & $1500 \mathrm{~cm}^{2}$ \\
\hline wal1 temperature & $100^{\circ} \mathrm{C}$ \\
\hline melt temperature & $1470^{\circ} \mathrm{C}$ \\
\hline crucible temperature & $1480^{\circ} \mathrm{C}$ \\
\hline average argon temperature & $250^{\circ} \mathrm{C}$ \\
\hline $\begin{array}{l}\text { effective temperature for radiation } \\
\text { (Stefans model) }\end{array}$ & $327^{\circ} \mathrm{C}$ \\
\hline convective heat transfer coefficient & $1.2433 \times 10^{-4}(\Delta \mathrm{T})^{1 / 3} \mathrm{~W} / \mathrm{cm}^{2} \mathrm{~K}$ \\
\hline $\begin{array}{l}\text { melt to crystal heat transfer } \\
\text { coefficient }\end{array}$ & $0.3265 \mathrm{~W} / \mathrm{cm}^{2} \mathrm{~K}$ \\
\hline thermal conductivity & $\begin{array}{l}0.98892408-9.4286595 \times 10^{-4} \mathrm{~T} \\
+2.889 \times 10^{-7} \mathrm{~T}^{2}, \mathrm{~W} / \mathrm{cm} \mathrm{K} \\
(\mathrm{T} \text { in Kelvin) }\end{array}$ \\
\hline emissivity of silicon crystal & $\begin{aligned} \varepsilon= & 0.64 \text { if } \mathrm{T}<1000 \mathrm{~K} \\
= & .9016-2.616 \times 10^{-4} \mathrm{~T} \\
& \text { if } \mathrm{T}>1000 \mathrm{~K}\end{aligned}$ \\
\hline emissivity of melt & 0.3 \\
\hline emissivity of crucible & 0.59 \\
\hline emissivity of wall & 0.59 \\
\hline
\end{tabular}




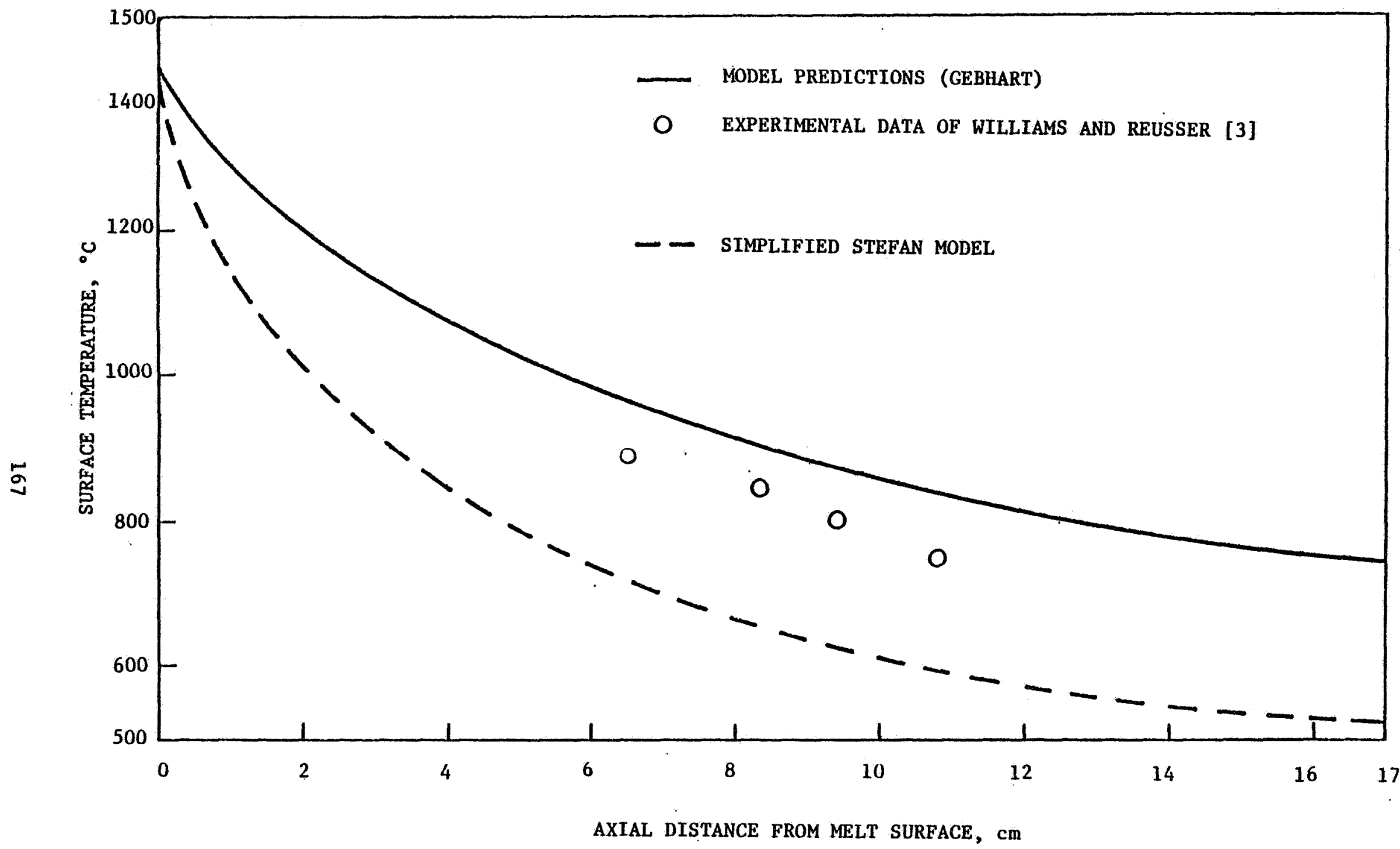

Figure 5. Predicted crystal surface temperatures based on Gebhart and Stefan models and experimental results of Williams and Reusser [3] 


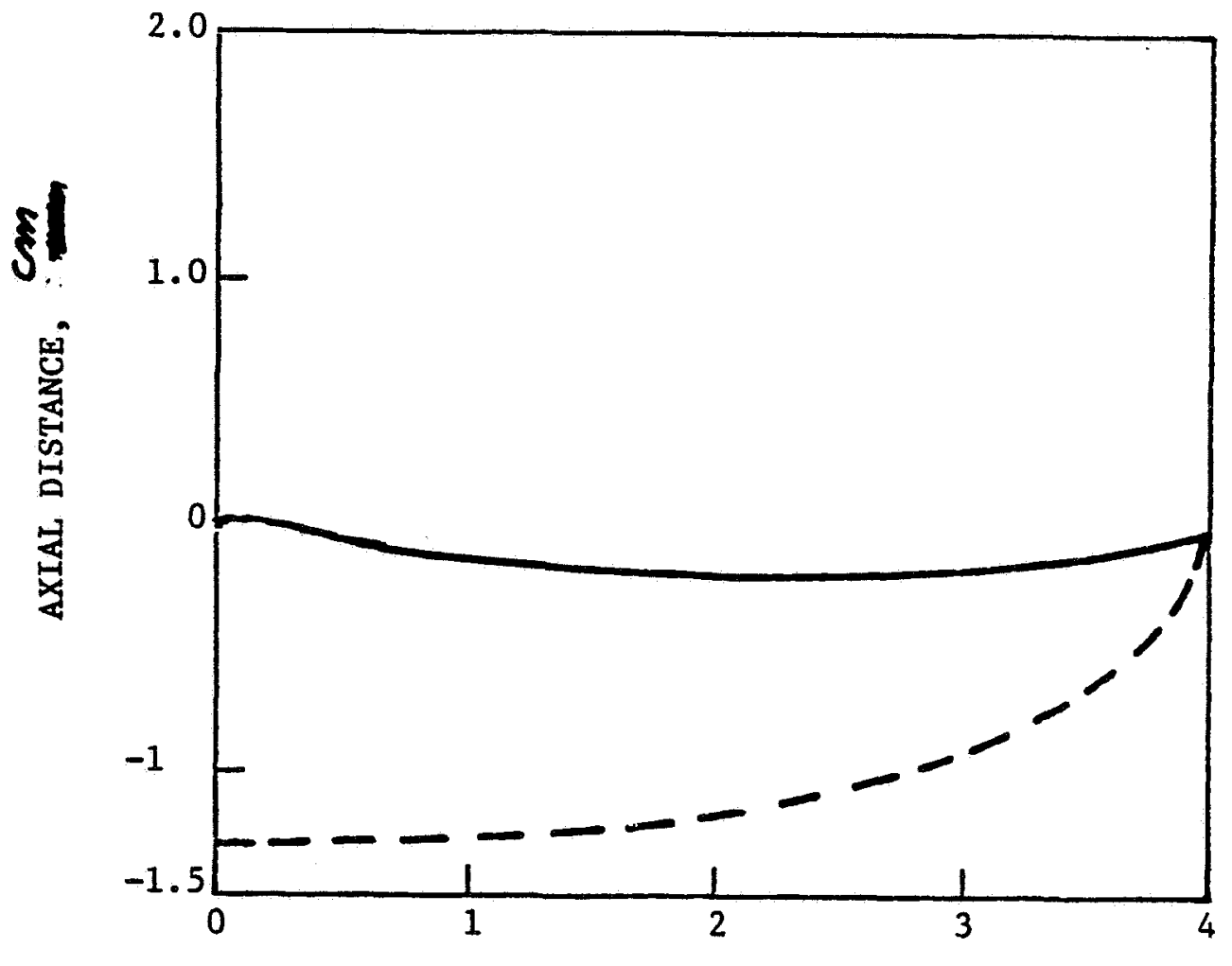

RADIAL DISTANCE, $\mathrm{cm}$

Figure 6. Interface shape calculated for the data of Table 2. - Gebhart analysis for radiation, --- Stefan model 


\section{Summary}

A FINITE ELEMENT ALGORITHM HAS BEEN DEVELOPED FOR EVALUATION OF THE TEMPERATURE PROFILES IN THE CRYSTAL AND FOR PREDICTION OF THE POSITION OF THE CRYSTAL-MELT INTERFACE.

IT IS SHOWN THAT ACCOUNTING PROPERLY FOR RADIATION EFFECTS CAN INFLUENCE CONSIDERABLY THE PREDICTIONS FOR THE TEMPERATURE PROFILE AND MELTCRYSTAL INTERFACE. 
SUMMARY (Cont'd)

THE DEVELOPED ALGORITHM, AT PRESENT, INCORPORATES

THE FOLLOWING SIMPLIFYING ASSUMPTIONS

- pseudo-steady state

- symmetry

- constant melt temperature

- constant heat transfer coefficient at melt-crystal interface

- no thermo capillary effect

- fixed crystal radius

COUPLING OF THIS MODEL WITH A REALISTIC HYDRODYNAMIC AND THERMOCAPILLARY MODEL IS NECESSARY AND IS CURRENTLY IN PROGRESS.

COMPARISON WITH EXPERIMENTAL DATA AND PARAMETER

SENSITIVITY STUDIES ARE ALSO ESSENTIAL. 
Recommendations

OUR UNDERSTANDING OF THE COMPLEXITIES OF THE

CZ (OR LECZ) PROCESS IS FAR FROM COMPLETE.

UNIVERSITY PERSONNEL AT A NUMBER OF LOCATIONS

MUST BE ENCOURAGED (AND FUNDED) TO CONTINUE THE WORK

IN THIS AREA,

COMPETITION AND OVERLAP OF COVERAGE OF CERTAIN TOPICS IS HELPFUL. INADEQUATE COVERAGE AND NEGLECT OF THESE PROBLEMS CAN ONLY HURT OUR COMPETITIVENESS IN THE FUTURE, 


\section{DISCUSSION}

WITT: I would like you to treat the inverse problem. Namely, we need an establishment of the boundary conditions, or the range of boundary conditions, under which in the desired thermal configuration the crystal in the melt can be achieved, rather than quantitative verification through modeling of adverse thermal configurations. I recognize that the inverse problem is infinitely more difficult to solve. What I think industry needs to know is, what are the required boundary conditions necessary to achieve optimized silicon growth? Not verification of the complexity of the heat transfer conditions through modeling.

DUDUKOVIC: Your point is well taken, but I think the two really go together. I don't see it at all incompatible in the process of learning the complexities, that you show that one should be thinking about sone other configurations in which asymmetry will not be a problem. Even if you go to those other configurations, it's still nice to have a quantitative rigorous model for well-defined situations.

WITT: I'm only trying to preserve realism, and the realism is that you can only sell the effort to industry if industry sees the direct impact. I think industry wants concrete input to systems design and the connection from what we are doing to that is obscure.

SCHWUTTKE: It looks like you are trying to calculate the position of the train after it left the station. The crystals are already grown and nothing happens anymore that I am concerned about. I need to know how to shape my interface.

DUDUKOVIC: In order to know where the interface shape is -- you are not going to get there just by knowing the meniscus. We also need to know the radiative heat fluxes and the conductive heat fluxes.

One has to start from someplace. Once you have solved the crystal problem right you can now couple that with any level of approximation for the meniscus and for the melt that you want. The three are coupled. You can not arrive at a one-line formula by which you can resolve the interface shape just by considering one of those effects.

MORRISON: I know for a fact that industry has been interested in your modeling. I think that when the models are built and verified you can go back and use the models as a tool to build a station.

Have you compared the interfaces of the terminations of grown crystals with the interface shapes that your model is generating?

DUDUKOVIC: That would be the wrong thing to do, because it would just demonstrate the effect of one factor on the position of that interface. This is exactly the trap that industrial people often fall into. They run out and say it doesn't match my experimental 
observations. One can make sense of complex phenomena by putting them together and the only way that putting them together can be done is through mathematics. There is no other way. Everything else is just handwaving. 